University of South Carolina

Scholar Commons

$1-16-2012$

\title{
Temperature Dependence of Current Conduction in Semi- Insulating 4H-SiC Epitaxial Layer
}

\author{
P. G. Muzykov \\ University of South Carolina - Columbia, muzykovp@engr.sc.edu \\ Ramesh Madhu Krishna \\ University of South Carolina, rmkrish55@gmail.com \\ K. C. Mandal \\ University of South Carolina - Columbia, mandalk@engr.sc.edu
}

Follow this and additional works at: https://scholarcommons.sc.edu/elct_facpub

Part of the Electrical and Electronics Commons

\footnotetext{
Publication Info

Published in Applied Physics Letters, Volume 100, Issue 3, 2012, pages 032101-1-032101-4.

(C) Applied Physics Letters 2012, American Institute of Physics

Muzykov, P. G., Krishna, R. M., \& Mandal, K. C. (17 January 2012). Temperature dependence of current conduction in semi-insulating 4H-SiC epitaxial layer. Applied Physics Letters, 100(3), \#032101. http://dx.doi.org/10.1063/1.3676270

http://scitation.aip.org/content/aip/journal/apl/100/3/10.1063/1.3676270

This Article is brought to you by the Electrical Engineering, Department of at Scholar Commons. It has been accepted for inclusion in Faculty Publications by an authorized administrator of Scholar Commons. For more information, please contact digres@mailbox.sc.edu.
} 


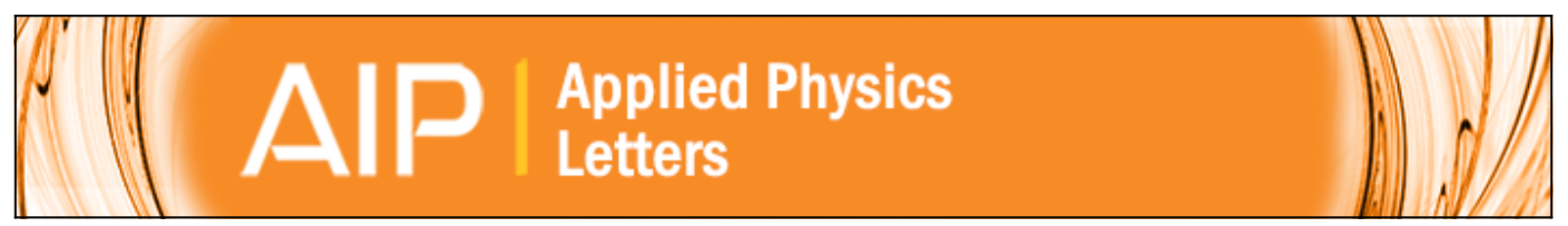

\section{Temperature dependence of current conduction in semi-insulating $4 \mathrm{H}-\mathrm{SiC}$ epitaxial} layer

Peter G. Muzykov, Ramesh M. Krishna, and Krishna C. Mandal

Citation: Applied Physics Letters 100, 032101 (2012); doi: 10.1063/1.3676270

View online: http://dx.doi.org/10.1063/1.3676270

View Table of Contents: http://scitation.aip.org/content/aip/journal/apl/100/3?ver=pdfcov

Published by the AIP Publishing

\section{Articles you may be interested in}

Highly sensitive $\mathrm{x}$-ray detectors in the low-energy range on n-type $4 \mathrm{H}-\mathrm{SiC}$ epitaxial layers

Appl. Phys. Lett. 101, 051111 (2012); 10.1063/1.4742741

Characterization of deep levels in n-type and semi-insulating $4 \mathrm{H}-\mathrm{SiC}$ epitaxial layers by thermally stimulated current spectroscopy

J. Appl. Phys. 111, 014910 (2012); 10.1063/1.3675513

Formation of a semi-insulating layer in n-type $4 \mathrm{H}-\mathrm{SiC}$ by electron irradiation

Appl. Phys. Lett. 98, 262106 (2011); 10.1063/1.3604795

Major deep levels with the same microstructures observed in n-type $4 \mathrm{H}-\mathrm{SiC}$ and $6 \mathrm{H}-\mathrm{SiC}$

J. Appl. Phys. 109, 013705 (2011); 10.1063/1.3528124

Chemical vapor deposition of $4 \mathrm{H}-\mathrm{SiC}$ epitaxial layers on porous $\mathrm{SiC}$ substrates

Appl. Phys. Lett. 78, 117 (2001); 10.1063/1.1337628

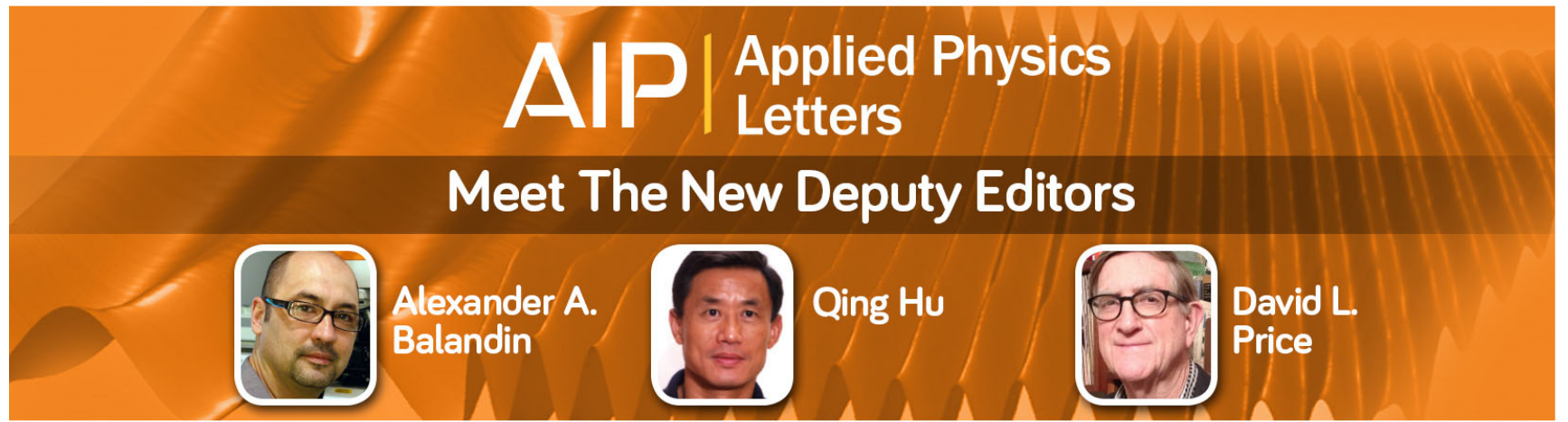




\title{
Temperature dependence of current conduction in semi-insulating 4H-SiC epitaxial layer
}

\author{
Peter G. Muzykov, Ramesh M. Krishna, and Krishna C. Mandal ${ }^{a)}$ \\ Department of Electrical Engineering, University of South Carolina, Columbia, South Carolina 29208, USA
}

(Received 10 August 2011; accepted 21 December 2011; published online 17 January 2012)

\begin{abstract}
We have investigated temperature dependence $(94 \mathrm{~K}-650 \mathrm{~K})$ of current conduction in semi-insulating $4 \mathrm{H}-\mathrm{SiC}$ epitaxial layer. The epitaxial layer was grown on highly doped n-type (0001) $4 \mathrm{H}-\mathrm{SiC}$ substrate using chemical vapor deposition with dichlorosilane precursor. The current-voltage (I-V) characteristics exhibited steps at $\sim 1 \mathrm{~V}$ and $\sim 70 \mathrm{~V}$ that were attributed to the filling of deep level centers by injected electrons. Correlation of the I-V characteristics with the results of thermally stimulated current measurements showed that deep centers peaked at $242 \mathrm{~K}, 285 \mathrm{~K}$, and $500 \mathrm{~K}$, were responsible for the steps in the I-V characteristics. Slow processes of the injected carrier capture on traps resulted in the I-V characteristic with negative differential resistance. (c) 2012 American Institute of Physics. [doi:10.1063/1.3676270]
\end{abstract}

Silicon carbide possesses a great potential for high power, high frequency, and high temperature electronics applications. ${ }^{1}$ Chemical vapor deposition (CVD) is usually used to produce high quality $\mathrm{SiC}$ epitaxial layers for device fabrication. Both $\mathrm{n}$ - and p-type $\mathrm{SiC}$ epitaxial layers have been achieved by doping with mainly nitrogen and aluminum, respectively. Growth of high purity semi-insulating (SI) epitaxial layers, essential for the development of certain type of devices such as radiation detectors ${ }^{2,3}$ and photoswitching devices, ${ }^{4}$ represent a challenging task since the semi-insulating property is achieved by a compensation mechanism involving intrinsic defects and their complexes, which are difficult to control. It is well known that electrical properties of epitaxial layers and devices are controlled by electrically active defects and impurities, creating deep and shallow energy levels in the band gap. For the development of high blocking voltage devices, it is important to understand the influence of deep levels on the device I-V characteristics, particularly on the device leakage current. The later depend on the injection properties of a contact and current conduction through the semiconductor itself. The current conduction in non-conducting materials has been extensively studied and the theory of current injection limited by spacecharge has been developed assuming Ohmic type of contacts acting as an infinite source of free electrons. ${ }^{5}$ This theory was deployed to interpret I-V characteristics in a large number of materials, namely $\mathrm{CdS}, \mathrm{ZnS}, \mathrm{AlN}, \mathrm{Si}, \mathrm{SiC}$, etc. Note that in practice, during development of advanced devices utilizing emergent material systems, it is often difficult to understand what causes high leakage current. This is due to the possible influence of a large number of factors such as crystallographic defects, surface leakage, non-Ohmic character of contacts, barrier non-uniformity, field enhancement at the contact edges, etc. This understanding is crucial in the development of advanced high voltage semiconductor devices. Therefore, studies revealing the physics and signatures of the above effects are highly demanded.

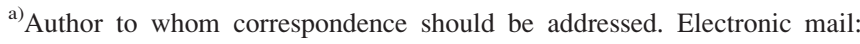
mandalk@cec.sc.edu.
}

In this study, we used a SI epitaxial layer grown on $8 \times 8 \mathrm{~mm}^{2}$ highly doped by nitrogen $4 \mathrm{H}-\mathrm{SiC}(0001)$ substrate, $8^{\circ}$ off-cut towards $[11 \overline{2} 0]$ direction. The epitaxial growth was carried out in a home-made hot-wall CVD system at $20 \mu \mathrm{m} / \mathrm{h}$ growth rate. Dichlorosilane $\left(\mathrm{SiH}_{2} \mathrm{Cl}_{2}\right.$, DCS $)$ and propane $\left(\mathrm{C}_{3} \mathrm{H}_{8}\right)$ were used as the precursors and hydrogen of $6 \mathrm{slm}$ was employed as the carrier gas. The dilution ratio during growth was $\sim 1000$. The flow rates of dichlorosilane and propane were maintained to obtain $\mathrm{C} / \mathrm{Si}$ ratio of 1.66. Before growth, in-situ hydrogen etching was performed at $1550{ }^{\circ} \mathrm{C}$ for $20 \mathrm{~min}$. The growth temperature and pressure were $1550^{\circ} \mathrm{C}$ and 80 Torr, respectively. No intentional dopants were used to grow semi-insulating epitaxial layer. The as-grown epitaxial layer was $19 \mu \mathrm{m}$ thick, with a specular surface. The epitaxial layer was examined using Nomarski optical microscopy to be free of morphological defects, except for one carrot defect which was located outside the contact area. The high frequency $(100 \mathrm{kHz})$ capacitance of the SI epitaxial layer measured using an annular mercury probe with $0.5 \mathrm{~mm}$ dia contact (MSI electronics model $\mathrm{Hg}$ 402) was low $(\sim 2 \mathrm{pF})$ and remained practically constant with applied bias indicating the semi-insulating nature of the epitaxial layer. The results of the transfer length method (TLM) measurement on the sister epitaxial layer confirmed its semi-insulating property.

To perform I-V and thermally stimulated current (TSC) measurements, nickel contacts $\sim 20 \mathrm{~nm}$ in thickness and $1 \mathrm{~mm}$ in diameter were formed on top of the epitaxial layer using lift-off process. Before that, the sample was treated using a standard Radio Corporation of America (RCA) cleaning process. Ni layer deposition was accomplished using an electron beam evaporation (e-beam) system equipped with the Sycon Instruments model STC-200 Deposition Rate Controller that was used to control the thickness of the deposited Ni layer.

Current-voltage characteristics of the as-deposited contacts were measured using Keithley 237 High Voltage Source Measure Unit. The measurements were done in darkness in the temperature range $94-650 \mathrm{~K}$ under vacuum $<10^{-4}$ Torr. The temperature of the sample was controlled by the thermal stage and temperature controller manufactured by MMR 

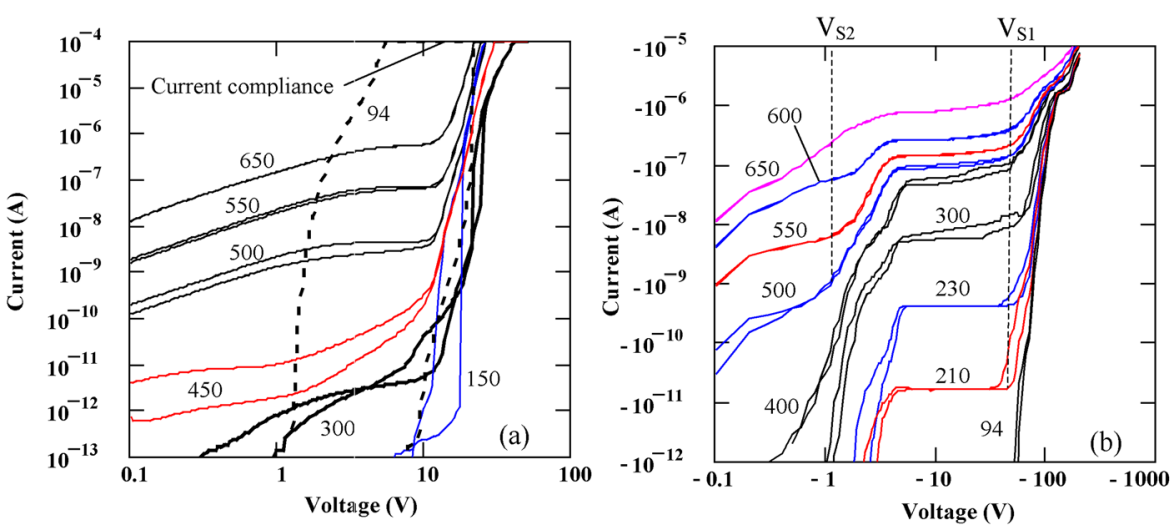

FIG. 1. (Color online) Forward (a) and reverse (b) I-V characteristics for the $1 \mathrm{~mm}$ dia. Ni contact to $\mathrm{SI} 4 \mathrm{H}-\mathrm{SiC}$ epitaxial layer obtained at various temperatures. The temperature tagged to each $\mathrm{I}-\mathrm{V}$ characteristic is in $\mathrm{K}$.
Technologies Inc. (model numbers R2400-25 and K20, respectively). Dual stair acquisition mode was used during $\mathrm{I}-\mathrm{V}$ measurements with $0 \mathrm{~V}$ default bias voltage.

The I-V characteristics of the Ni contact to the SI $4 \mathrm{H}-$ $\mathrm{SiC}$ epitaxial layer obtained at various temperatures are shown in Fig. 1. As can be seen from Fig. 1, the I-V characteristics obtained at positive and negative polarities of the applied voltage are asymmetrical meaning that high currents $(>10 \mu \mathrm{A})$ were reached at much lower positive than negative voltage. Therefore, in further discussion, we use terms forward and reverse I-V characteristics for the positive and negative polarity of the applied voltage, respectively. High forward voltage of about $\sim 15 \mathrm{~V}$ indicates significant voltage drop across the epitaxial layer. The asymmetry between forward and reverse I-V characteristics are believed to be caused by the difference in the potential distribution at the $\mathrm{Ni} / \mathrm{SI}-\mathrm{SiC}$ and $\mathrm{SI}-\mathrm{SiC} / \mathrm{n}^{+} \mathrm{SiC}$ interfaces. The suggested energy band diagram of the studied structure in thermodynamic equilibrium at room temperature is schematically shown in Fig. 2. This energy diagram was obtained assuming no interface states and pinning of the Fermi level in SI SiC close to the middle of the band gap by the partially unoccupied electron trap centers as discussed later. We used $\sim 4.0 \mathrm{eV}$ for the electron affinity of $4 \mathrm{H}-\mathrm{SiC}$ (Ref. 6) and $\sim 5.2 \mathrm{eV}$ for the Ni work function. ${ }^{7}$ Since the I-V characteristics were measured using dual stair sequence, each I-V characteristic shown in Fig. 1 consists of two brunches corresponding to ramping the voltage up and down. These brunches did not coincide at temperatures $<600 \mathrm{~K}$ resulting in a hysteresis. The reverse I-V characteristics (Fig. 1(b))

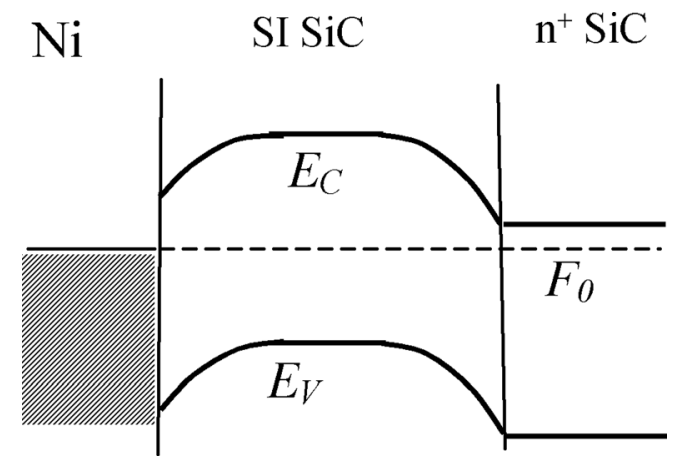

FIG. 2. Suggested energy band diagram of the studied structure at room temperature (deep levels in SI SiC are not shown). exhibited step-like features. Step 1 with $\mathrm{V}_{\mathrm{S} 1} \approx 70 \mathrm{~V}$ was observed at temperatures $>200 \mathrm{~K}$ and step 2 with $\mathrm{V}_{\mathrm{S} 2} \sim 1 \mathrm{~V}$ occurred at temperatures $>350 \mathrm{~K}$. In the theory of current injection into solids limited by space charge, ${ }^{5}$ the step in the $\mathrm{I}-\mathrm{V}$ characteristic correspond to the ultimate filling of trap centers with the energy $E_{t}$ by injected carriers, which occurs at the applied voltage $V_{S}$ given by

$$
V_{S}=\frac{q L^{2}}{2 \varepsilon} \times p_{t, 0}
$$

where $p_{t, 0}=\frac{N_{t}}{g} \exp \left[\frac{E_{t}-F_{o}}{k T}\right]$ is the concentration of trap centers unoccupied by the injected carriers, $E_{t}$ is the activation energy of trap, $k$ is the Boltzmann's constant, $L$ is the thickness of the epitaxial layer, $q$ is the electronic charge, $\varepsilon$ is the permittivity of the material, $F_{o}$ is the Fermi energy, $N_{t}$ is the trap density, and $g$ is the degeneracy factor. Applying Eq (1) to the step voltages $\mathrm{V}_{\mathrm{S} 2} \approx 1 \mathrm{~V}$ and $\mathrm{V}_{\mathrm{S} 1} \approx 70 \mathrm{~V}$, we obtained the concentrations of the trap centers unoccupied by the injection carriers $\sim 3 \times 10^{12} \mathrm{~cm}^{-3}$ and $\sim 2 \times 10^{14} \mathrm{~cm}^{-3}$, respectively. The later concentration represents total trap concentration if we assume that all traps corresponding to step 1 were empty in the beginning of the I-V characteristic $(V=0)$.

The deep levels in the epitaxial layer used in this work were characterized by TSC spectroscopy. TSC measurements were conducted in the temperature range 94-620 K in vacuum $<1 \times 10^{-4}$ Torr at $0 \mathrm{~V}$ and $\pm 5 \mathrm{~V}$ bias voltages applied to the top Ni contact. The trap filling was achieved by illuminating the samples at $94 \mathrm{~K}$ using UVP model UVM57 Handheld UV Lamp specified to produce $302 \mathrm{~nm}$ UV light. The detailed description of our TSC measurement setup is available in our earlier publication. ${ }^{8}$ We have used the variable heating rate $\operatorname{method}^{9}$ to determine the trap activation energy and capture cross-section. The details of the calculation can be found in our work ${ }^{8}$ and in the Refs. 10 and 11. Briefly, the TSC spectra were obtained at $4 \mathrm{~K} / \mathrm{min}, 8 \mathrm{~K} / \mathrm{min}$, and $15 \mathrm{~K} / \mathrm{min}$ heat rates revealing a given trap center by a peak with a maximum temperature $T_{m}$ at a given heat rate. Therefore, for a given trap center, we have a set of three $T_{m}$, which provided the Arrhenius plot for finding the trap activation energy from its slope. Using the activation energies, the temperature independent capture cross-sections were then found by fitting the experimental curves of TSC spectra by the theoretical ones calculated by 


$$
I_{T S C}=\sum_{i} I_{i},
$$

where $I_{T S C}$ is the total thermally stimulated current, $i$ is the discrete energy level number, and $I$ is the current produced by the individual discrete energy level, given by ${ }^{11}$

$$
I=I_{0} \exp \left[-\frac{E_{a}}{k T}-\frac{k D_{t}}{\beta E_{a}} T^{4} e^{-E_{a} / k T}\left(1-4 \frac{k T}{E_{a}}+20\left(\frac{k T}{E_{a}}\right)^{2}\right)\right],
$$

where $I_{0}=N_{T} e \mu A \tau E D_{t} T^{2}, N_{T}$ is the density of the filled traps at the beginning of the temperature ramp, $e$ is the electronic charge, $\mu$ is the carrier mobility, $A$ is the area of the electrode, $\tau$ is the free carrier lifetime, $E$ is the electric field, $k$ is the Boltzmann's constant, $T$ is the absolute temperature, $D_{t}=3 \times 10^{21} \sigma\left(m^{*} / m_{0}\right), \sigma$ is the capture cross section, $m_{0}$ and $m^{*}$ are the electron rest and effective mass, respectively, $\beta$ is the heat rate, and $E_{a}$ is the trap activation energy.

Since the TSC spectra measured at $\pm 5 \mathrm{~V}$ (not shown) were strongly affected by the leakage currents, identification of trap activation energy and capture cross section was accomplished using TSC spectra at $0 \mathrm{~V}$ shown in Fig. 3. Note that similar measurements at $0 \mathrm{~V}$ bias were used to characterize deep levels in SI GaAs samples ${ }^{12}$ and the thermally stimulated current was attributed to thermoelectric effect (TEE) caused by a small temperature gradient between front and back surfaces of the sample $(\sim 1 \mathrm{~K}$ across $\sim 500 \mu \mathrm{m}$ thick sample). Since the polarity of TEE current is sensitive to the type of carriers, the positive peaks in Fig. 3 would represent hole traps and the negative peaks-electron traps. We have distinguished 5 peaks (A-E) in the TSC spectra in Fig. 3. The Arrhenius plots of the traps A-D are shown in Fig. 4. The summary of trap parameters extracted from our TSC measurements is given in Table I. Peaks A and B with activation energy $\sim 0.2 \mathrm{eV}$ can be produced by $\mathrm{Al}, \mathrm{B}$ impurities, and complexes such as Al-related $L$-center with reported ionization energies $0.23 \mathrm{eV},(0.23-0.28 \mathrm{eV})$, and $0.24 \mathrm{eV}$ above valence band edge, respectively. ${ }^{13,14}$ Such an assignment complies with TSC studies of SI 4H-SiC (Ref. 10) where $\mathrm{Al}$ related trap with $E_{a}=0.22 \mathrm{eV}$ was peaked at $105 \mathrm{~K}$. We have tentatively assigned peak $\mathrm{C}$ at $\sim 242 \mathrm{~K}$ $\left(E_{a}=0.57 \mathrm{eV}\right)$ to the $\mathrm{Z}_{1 / 2}$ center. ${ }^{10,13,14}$ Although the reported activation energy of $Z_{1 / 2}$ center $(0.63-0.68 \mathrm{eV})$ and the typical peak temperature are somewhat higher than that

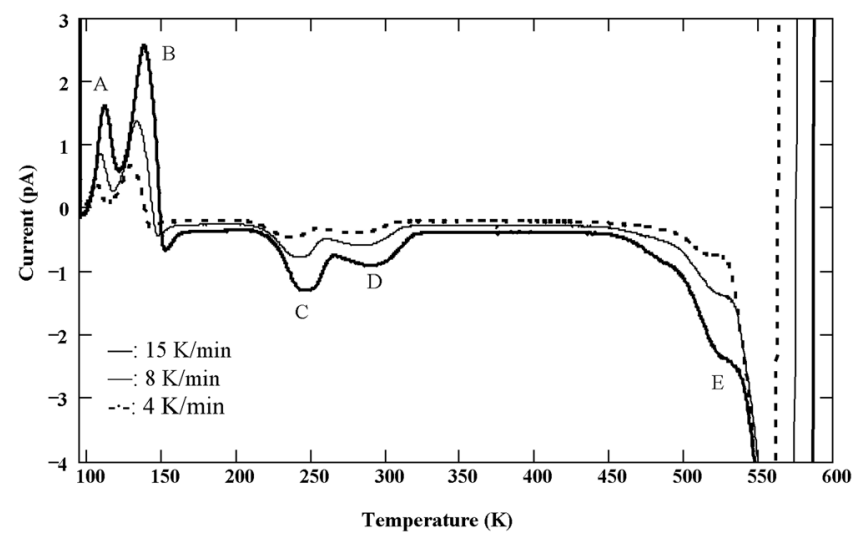

FIG. 3. TSC spectra of the SI SiC epitaxial layer at $0 \mathrm{~V}$ bias voltage.

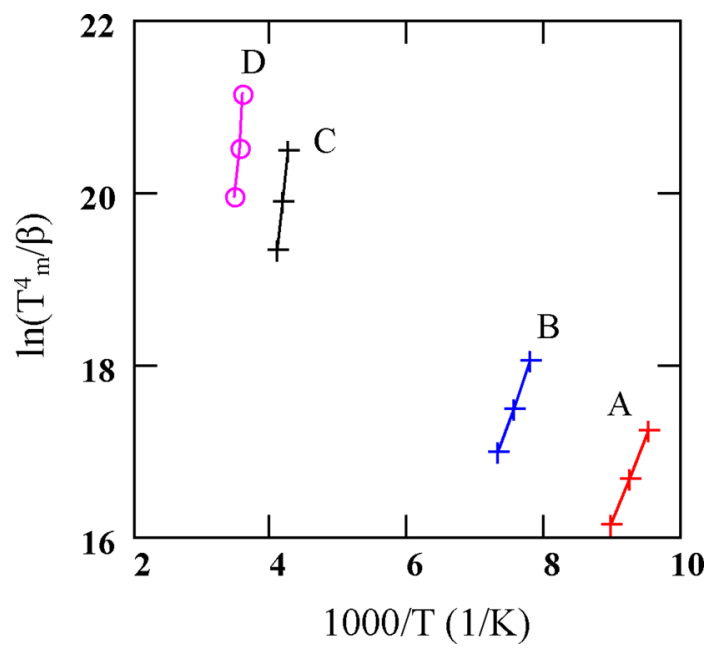

FIG. 4. (Color online) Arrhenius plots obtained from TSC spectra of the SI $\mathrm{SiC}$ epitaxial layer at $0 \mathrm{~V}$ bias voltage.

for peak $\mathrm{C}$, this is the only electron trap candidate for this peak that we were able to find in the published literature. Peak D matches with electron trap $I L_{1}$ (Ref. 15) at $\left(E_{C}-0.87 \mathrm{eV}\right)$ and capture cross-section $\sim 1 \times 10^{-14} \mathrm{~cm}^{2}$, which are fairly close to that found from our TSC measurements. It is suggested that a complex involving two nitrogen atoms $\left(\mathrm{N}_{\mathrm{C}}-\mathrm{N}_{\mathrm{i}}\right)$ or a split interstitial on $\mathrm{C}$ site $(\mathrm{N}-\mathrm{N})_{\mathrm{C}}$ produce $I L_{l}$ center although $\mathrm{V}_{\mathrm{C}}, \mathrm{Si}_{\mathrm{C}}$, or $\mathrm{Si}_{\mathrm{i}}$ related defects are also a possibility. ${ }^{15}$ Further investigation is required to find the activation energy and capture cross section of the trap centers associated with feature $\mathrm{E}$ since its peak was swamped by high stray current. The high peaking temperature of $\mathrm{E}$ center implies its high activation energy possibly close to the middle of the band gap. The trap centers with activation energies close to the middle of the bandgap were reported for as grown $4 \mathrm{H}-\mathrm{SiC}$ epitaxial layers ${ }^{15,16}$ and bulk SI $4 \mathrm{H}-\mathrm{SiC}$ (Refs. 8, 17, and 18) and were attributed to intrinsic defects and their complexes.

In order to correlate the steps in the I-V characteristic with trap centers revealed by TSC measurements, note that the larger step voltage in the I-V characteristic correspond to filling the trap centers with smaller ionization energy. ${ }^{5}$ Therefore, comparing the I-V characteristics in Fig. 1(b) with TSC spectra in Fig. 3, we conclude that $V_{S 2}$ corresponds to ultimate filling of trap centers $E$, whereas $V_{S I}$ corresponds to ultimate filling of trap centers $C$ and $D$. The large

TABLE I. Trap parameters in SI 4H-SiC epitaxial layer deduced from TSC

\begin{tabular}{|c|c|c|c|c|}
\hline $\begin{array}{c}\text { TSC } \\
\text { peak \# }\end{array}$ & $T_{m}(\mathrm{~K})$ & $\begin{array}{c}\text { Activation } \\
\text { energy } \\
(\mathrm{eV})\end{array}$ & $\begin{array}{c}\text { Capture } \\
\text { cross-section } \\
\left(\mathrm{cm}^{2}\right)\end{array}$ & $\begin{array}{l}\text { Possible defects } \\
\text { or impurities }\end{array}$ \\
\hline $\mathrm{A}$ & $105-112$ & 0.19 & $\sim 10^{-18}$ & Al, B, L-center (Refs. 13 \\
\hline B & $128-137$ & $\sim 0.2$ & - & and 14) \\
\hline $\mathrm{C}$ & $236-247$ & 0.57 & $\sim 2 \times 10^{-16}$ & $\begin{array}{c}\mathrm{Z}_{1 / 2} \text { (Refs. 10, 13, } \\
\text { and 14) }\end{array}$ \\
\hline D & $280-290$ & $0.82-0.87$ & $\sim 10^{-13}$ & $I L_{l}($ Ref. 15) \\
\hline $\mathrm{E}$ & $\sim 525$ & - & - & Intrinsic defects \\
\hline
\end{tabular}
measurements at $0 \mathrm{~V}$. 


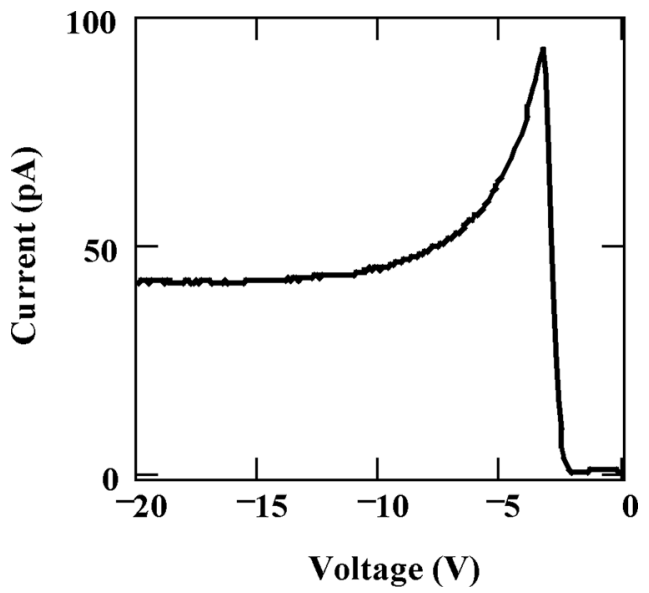

FIG. 5. I-V characteristic with NDR obtained at room temperature.

hysteresis in forward I-V characteristic at $94 \mathrm{~K}$ is obviously caused by traps $A$ and $B$.

Next, we report on the I-V characteristic with negative differential resistance (NDR) obtained for the studied structure at room temperature (Fig. 5). We suggest that the NDR is caused by slow processes of the injected carrier capture on traps as explained by the following. Ramping up the voltage during I-V measurement results in the barrier lowering and electron injection into the SI epitaxial layer. The increase of the rate of electron injection depends on how fast the applied voltage is ramped up. If the trapping rate of the injected curriers does not follow the injection rate increase, the current will initially increase exceeding the steady state current. Following trap filling causes decrease of the concentration of the injected electrons in the conduction band which results in the current decrease and NDR.

In conclusion, we have investigated the I-V characteristics of $\mathrm{Ni}$ contacts to $\mathrm{SI} 4 \mathrm{H}-\mathrm{SiC}$ epitaxial layers grown by CVD using dichlorosilane precursor. The I-V characteristics exhibited steps at $\sim 1 \mathrm{~V}$ and $\sim 70 \mathrm{~V}$ that we attributed to ultimate filling of deep levels using the theory of space-charge limited currents. Correlation of I-V characteristics with the results of thermally stimulated current measurements showed that deep centers peaked at $>500 \mathrm{~K}$ and at $\sim 242 \mathrm{~K}\left(E_{a} \sim 0.57 \mathrm{eV}\right)$ and $\sim 285 \mathrm{~K}\left(E_{a} \sim 0.84 \mathrm{eV}\right)$ were responsible for the steps in the $\mathrm{I}-\mathrm{V}$ characteristics. Slow processes of the injected carrier capture on traps resulted in the I-V characteristic with NDR.

One of the authors (Krishna C. Mandal) acknowledges partial financial support provided by Los Alamos National Laboratory/DOE (Grant No. 143479). The authors are thankful to Professor Tangali S. Sudarshan for helpful discussion and Dr. Haizheng Song for $\mathrm{SiC}$ epitaxial growth.

${ }^{1}$ H. Matsunami, Microelectron. Eng. 83, 2 (2006).

${ }^{2}$ F. Nava, G. Bertuccio, A. Cavallini, and E. Vittone, Meas. Sci. Technol. 19, 102001 (2008).

${ }^{3}$ K. C. Mandal, R. M. Krishna, P. G. Muzykov, S. Das, and T. S. Sudarshan, IEEE Trans. Nucl. Sci. 58, 1992 (2011).

${ }^{4}$ K. S. Kelkar, N. E. Islam, C. M. Fessler, and W. C. Nunnally, J. Appl. Phys. 98, 093102 (2005).

${ }^{5}$ M. A. Lampert and P. Mark, Current Injection in Solids (Academic, New York, 1970).

${ }^{6}$ T. V. Blank, Yu A. Goldberg, E. V. Kalinina, O. V. Konstantinov, A. O. Konstantinov, and A. Hallén, Semicond. Sci. Technol. 20, 710 (2005).

${ }^{7}$ CRC Handbook of Chemistry and Physics, edited by D. R. Lide, 89th ed. (CRC, Boca Raton, 2008).

${ }^{8}$ K. C. Mandal, P. G. Muzykov, R. Krishna, T. Hayes, and T. S. Sudarshan, Solid State Commun. 151, 532 (2011).

${ }^{9}$ K. G. Lynn and K. A. Jones, Part I. Physics, CdTe-based Nanostructures, CdTe-based Semimagnetic Semiconductors, Defects, edited by R. Triboulet and P. Siffert, 1st ed. (Elsevier, Oxford, 2010).

${ }^{10}$ Z.-Q. Fang, B. Claflin, D. C. Look, L. Polenta, and W. C. Mitchel, J. Electron. Mater. 34, 336 (2005).

${ }^{11}$ M. Pavlovic and U. V. Desnica, J. Appl. Phys. 84, 2018 (1998).

${ }^{12}$ Z. C. Huang, K. Xie, and C. R. Wie, Rev. Sci. Instrum. 62, 1951 (1991).

${ }^{13}$ J. Zhang, L. Storasta, J. P. Bergman, N. T. Son, and E. Janzén, J. Appl. Phys. 93, 4708 (2003).

${ }^{14}$ A. A. Lebedev, Semiconductors 33, 107 (1999).

${ }^{15}$ I. Pintilie, L. Pintilie, K. Irmscher, and B. Thomas, Mater. Sci. Forum 433-436, 463 (2003).

${ }^{16}$ K. Danno and T. Kimoto, J. Appl. Phys. 101, 103704 (2007).

${ }^{17}$ J. R. Jenny, St. G. Müller, A. Powell, V. F. Tsvetkov, H. M. Hobgood, R. C. Glass, and C. H. Carter, Jr., J. Electron. Mater. 31, 366 (2002).

${ }^{18}$ N. T. Son, B. Magnusson, Z. Zolnai, A. Ellison, and E. Janzén, Mater. Sci. Forum 457-460, 437 (2004). 